\title{
Victims and Perpetrators
}

[SF blogs.Ise.ac.uk/polis/2015/06/25/victims-and-perpetrators/

This article is by Dr Bart Cammaerts

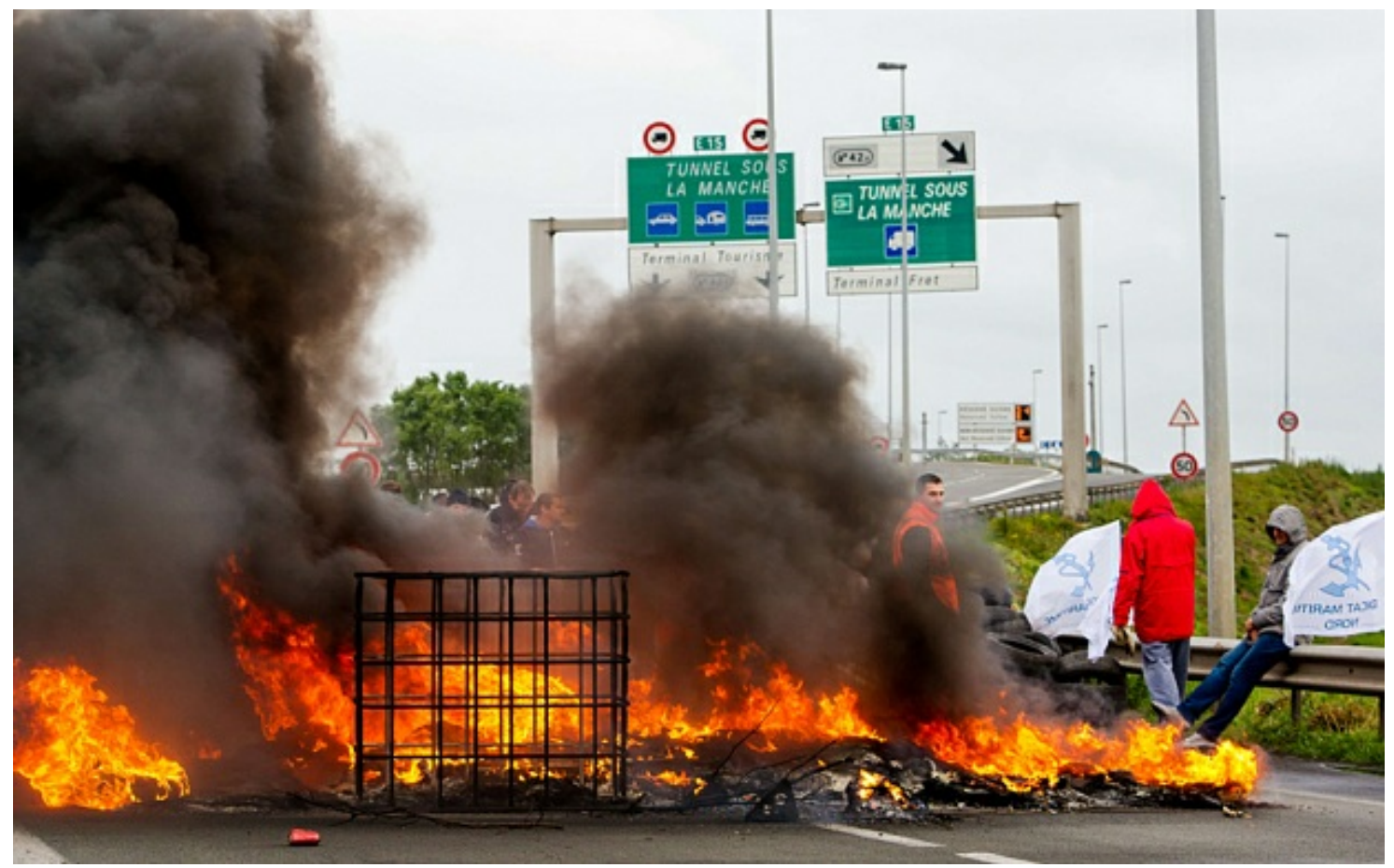

There is something striking (pun intended) about the current reporting by the UK media on the disruptive actions enacted by ferry employees in Calais. There has been little or no attention in the UK media for the reasons why the employees of the Ferry company MyFerryLink got so angry that they felt it necessary to not only strike, but also block Calais harbour and crucially the Eurotunnel and ultimately also the Eurostar crossings from France into the UK and vice versa. No interviews with local union leaders, no attempt to try to understand or provide a forum to hear their side of the story. In much of the reporting there is not even a mention of the underlying reasons for and frustrations that led to the industrial direct actions in the first place. Instead, the UK media's attention is firmly fixated on the impact of the strike, on its consequences, rather than on its causes.

Hence we see a deluge of reports about the disruption, about the 'strike mayhem' * as a prominent Left-leaning UK newspaper described it, or about the contentious issue of immigration and refugees trying to 'take advantage' of the 'travel chaos'. Regarding the latter there is clearly an implicit xenophobia inherent to much of the reporting, invoking the prospect of the UK being 'inundated' with immigrants, all trying to 'get into the UK', representing the displaced and destitute as Folk Devils, ... as illegitimate 'bogus asylum seekers', dixit The Daily Mail.

Besides this, when it comes to strikes and especially anarcho-syndicalist direct action, a deeply negative representation and vilification by the UK media has a long-standing legacy (see Glasgow Media Group). The starting point in these media representations is that striking and workers revolting against the exploitation by employers and/or indeed by the State protecting employers' interests, is not legitimate, and represents a nuisance for other, real, 'ordinary', innocent working people. In other words, it is not the employees who face the sack and fight for their rights that are the victims, but those 'innocent' people who see their day or indeed evening/night disrupted, they are the genuine and true victims, while the strikers are the perpe'traitors'.

What is sad in this regard, is that these journalistic and ideological logics which shape the reporting of disruptive industrial actions and strikes apply across the media landscape in the UK and not only to the right-wing media. 
(Although The Telegraph did post a short article outlining some reasons for the strike.) In general however, union leaders are very rarely given a voice in the UK public sphere and if they are, it is to ridicule them and to illustrate the gross illegitimacy of their demands and tactics. As a result of all this, not many people in the UK really understand or know precisely why the employees of the French ferry company are so angry, especially at the UK and why they disrupted the cross-channel traffic in such a rigorous and aggressive way.

MyFerryLink used to be the ailing ferry company SeaFrance, owned by the French publicly owned railway company. After the liquidation of SeaFrance in 2012 at the loss of almost 2,000 jobs, Eurotunnel, the company exploiting the tunnel-link between Calais (France) and Folkestone (UK), bought three vessels of SeaFrance and started operating its own ferry service between Calais and Dover, going into competition with UK's P\&O and the Danish DFDS Seaways. MyFerryLink employed 600 people, a mere fraction of what SeaFrance employed, but all employees became participants of a workers' cooperative, which in France is called a société coopérative et participative, to protect their rights and above all to protect levels of employment.

However, in response to complaints by its (UK- and Danish based) competitors and pushed by rulings of the British Competition and Markets Authority (CMA), Eurotunnel has been forced to sell MyFerryLink to its Danish competitor, ultimately leading to less competition, and above all leading to the breaking-up of the power of the workers' cooperative, and with it the protections for rights and guarantees of employment that were fought for by them. This might just explain why the strikers were so keen to target the UK and why a French minister said today that this just might possibly happen again in the near future...

$\left.{ }^{*}\right)$ The Guardian changed its headline from 'Cross-channel services returning to normal after strike mayhem' in the morning to the more neutral 'Calais: Eurostar, Eurotunnel and ferry services return to normal' later in the day.

\section{By Bart Cammaerts}

- Copyright (C 2014 London School of Economics and Political Science 